\title{
Synthesis of a Layered Organic-Inorganic Nanohybrid of 4-Chlorophenoxyacetate-zinc-Layered Hydroxide with Sustained Release Properties
}

\author{
Mohd Zobir Hussein, ${ }^{1,2}$ Nor Farhana binti Nazarudin, ${ }^{1}$ \\ Siti Halimah Sarijo, ${ }^{3}$ and Mohd Ambar Yarmo ${ }^{4}$ \\ ${ }^{1}$ Department of Chemistry, Faculty of Science, Universiti Putra Malaysia (UPM), Selangor, 43400 Serdang, Malaysia \\ ${ }^{2}$ Advanced Materials and Nanotechnology Laboratory, Institute of Advanced Technology (ITMA), Universiti Putra Malaysia (UPM), \\ Selangor, 43400 Serdang, Malaysia \\ ${ }^{3}$ Faculty of Applied Science, MARA University of Technology (UiTM), Selangor, 40450 Shah Alam, Malaysia \\ ${ }^{4}$ Department of Chemistry, Faculty of Science and Technology, National University of Malaysia (UKM), Selangor, \\ 43400 Bangi, Malaysia
}

Correspondence should be addressed to Mohd Zobir Hussein, mzobir@science.upm.edu.my

Received 27 July 2011; Accepted 26 August 2011

Academic Editor: Li-Hong Liu

Copyright ( $) 2012$ Mohd Zobir Hussein et al. This is an open access article distributed under the Creative Commons Attribution License, which permits unrestricted use, distribution, and reproduction in any medium, provided the original work is properly cited.

\begin{abstract}
A zinc-layered hydroxide-4-chlorophenoxy acetate (4CPA) organic-inorganic nanohybrid was prepared using a simple direct reaction of 4CPA anions with $\mathrm{ZnO}$ under an aqueous environment to be used as a controlled release formulation of the herbicide, 4CPA. The concentration of the active agent, 4CPA, was found to be a controlling factor for the formation of a pure phase wellordered nanolayered hybrid in which it could be synthesised at $0.2 \mathrm{M} 4 \mathrm{CPA}$. ZnO shows a well-defined grain structure of variable size in the nanometre range. However, the formation of the 4CPA-ZLH nanohybrid resulted in a flake-like fibrous structure. On heating at $500^{\circ} \mathrm{C}$ for $5 \mathrm{~h}$ under atmospheric conditions, the nanohybrid transformed back to a well-defined grain structure, as previously observed with the starting material, $\mathrm{ZnO}$. The release of 4CPA was found to occur in a controlled manner and was generally governed by pseudo-second-order kinetics.
\end{abstract}

\section{Introduction}

Layered metal hydroxide compounds with inorganic brucitelike structures can be generally classified into two major types, layered double hydroxides (LDHs) and layered metal hydroxides (LMHs). They can be represented by the general formula, $\left[\mathrm{M}^{2+}{ }_{1-x} \mathrm{M}^{3+}{ }_{x}(\mathrm{OH})_{2}\right]^{x+}\left(\mathrm{A}^{m-}\right)_{x / m} \cdot \mathrm{nH}_{2} \mathrm{O}$ and $\mathrm{M}^{2+}(\mathrm{OH})_{2-x}\left(\mathrm{~A}^{n-}\right)_{x / n} \cdot m \mathrm{H}_{2} \mathrm{O}$, respectively, where $\mathrm{M}^{2+}$ is a divalent cation $\left(\mathrm{Ca}^{2+}, \mathrm{Mg}^{2+}, \mathrm{Zn}^{2+}, \mathrm{Co}^{2+}, \mathrm{Ni}^{2+}, \mathrm{Cu}^{2+}\right.$, $\left.\mathrm{Mn}^{2+}\right), \mathrm{M}^{3+}$ is a trivalent cation $\left(\mathrm{Al}^{3+}, \mathrm{Cr}^{3+}, \mathrm{Fe}^{3+}, \mathrm{Co}^{3+}\right.$, $\left.\mathrm{Ni}^{3+}, \mathrm{Mn}^{3+}\right)$ and $\mathrm{A}^{m-}$ is an interlayer anion $\left(\mathrm{Cl}^{-}, \mathrm{NO}^{3-}\right.$, $\mathrm{ClO}^{4-}, \mathrm{CO}^{3-}, \mathrm{SO}_{4}{ }^{2-}$, and many other inorganic anions). For LDH, the $x$ value is the charge density, that is, the molar ratio of $\mathrm{M}^{3+} /\left(\mathrm{M}^{2+}+\mathrm{M}^{3+}\right)[1,2]$. LMH consists of two parts: positively charged brucite-like inorganic layers and exchangeable anions and water molecules in the interlayer.
These properties give LMH wide applications in industrial and environmental research from catalysts [3] to antacids $[4]$ and from magnetic materials $[5,6]$ to controlled release formulations of various active agents such as DNA [7], drugs $[8,9]$, and agrochemicals [10-15].

One LMH which has been the subject of intense research lately is zinc-layered hydroxide (ZLH). This is due the fact that ZLH has very similar properties to those of LDH. The 2D layered inorganic material is composed of layers with octahedral coordinated zinc cations, in which $1 / 4$ of them are displaced out of the layer, leaving an empty octahedral site which forms cationic centres tetrahedrically coordinated to the top and bottom of the octahedral sheet. Water molecules occupy the apices, and nitrate counter ions are free between the interlayers [16]. 


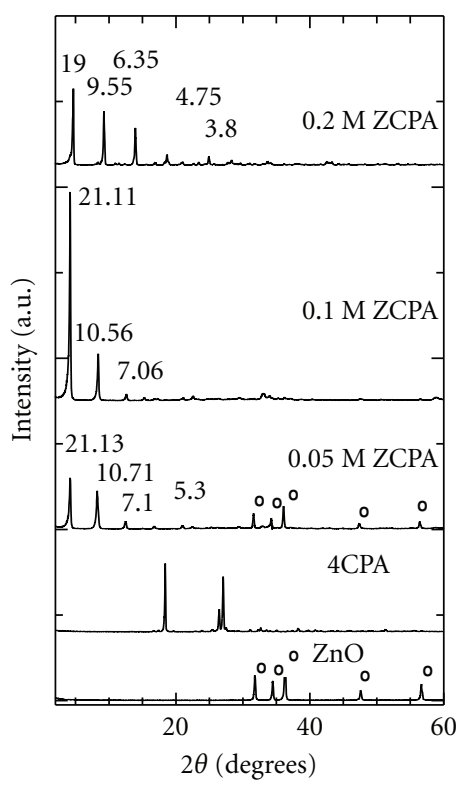

Figure 1: PXRD patterns of $\mathrm{ZnO}, 4 \mathrm{CPA}$, and ZCPA nanohybrids prepared at $0.05,0.10$, and $0.20 \mathrm{M} 4 \mathrm{CPA}(\mathrm{o}=\mathrm{ZnO}$ phase, peak from left to right is for 100, 002, 101, 102, 110 reflection. Assignment of other peaks is given in Table 1 ).

Controlled release formulations (CRF) have been used as an approach to exploit the most effective use of herbicides and at the same time to prevent environmental pollution [17]. Ideally, the CRF should be able to release herbicides at a level required to manage the crops, therefore preventing problems such as leaching, evaporation, degradation, and excessive use of harmful chemicals [18]. Various matrices have been proposed for use as pesticide CRF. The active agent should be immobilised or intercalated into an inert matrix and gradually released over time [19]. The use of natural and synthetic clay-type materials in the preparation of CRF is of current interest due to their tailor-made properties and relatively low cost of preparation.

In this study, we discuss our work on the intercalation of $4 \mathrm{CPA}$, an herbicide, into the interlayer of ZLH by a simple synthesis method, that is, by the direct reaction of $\mathrm{ZnO}$ with 4CPA under an aqueous environment for the formation of a new controlled release formulation of the organic-inorganiclayered nanohybrid type. In addition, the controlled release property of the resulting nanohybrid will be also discussed.

\section{Materials and Methods}

All chemicals used in this synthesis were obtained from various chemical suppliers and used without further purification. All solutions were prepared using deionised water with resistivity of $18.2 \mathrm{M} \Omega-\mathrm{cm}$.

In this study, $0.05 \mathrm{gZnO}$ (Acros), was discharged into $100 \mathrm{~mL}$ deionised water. Solutions of 4CPA (Aldrich) with concentrations of $0.025-0.1 \mathrm{M}$ were added to the $\mathrm{ZnO}$ solutions and aged at $70^{\circ} \mathrm{C}$ in an oil bath shaker for 18 hours. The synthesised material was centrifuged, thoroughly washed with deionised water and dried in an oven at $70^{\circ} \mathrm{C}$.
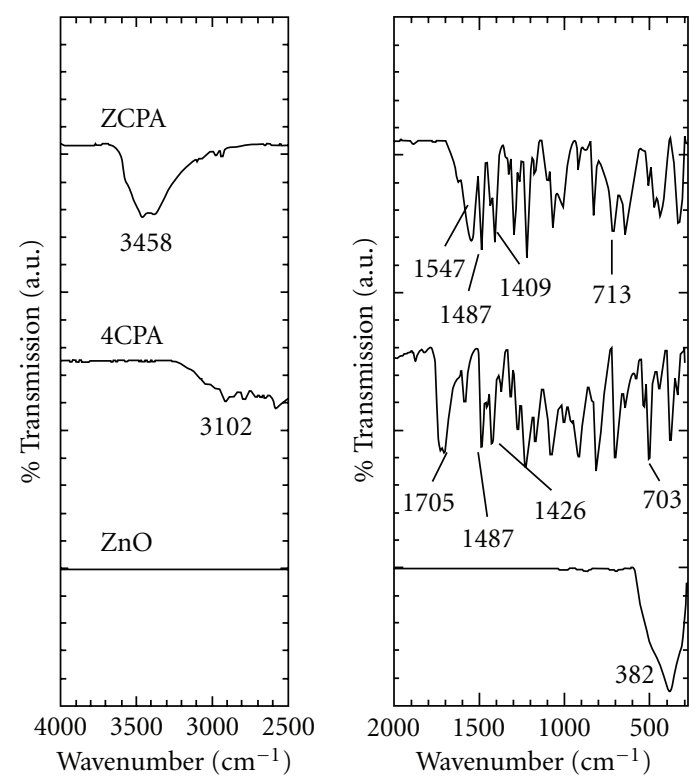

FIGURE 2: FTIR spectra of $\mathrm{ZnO}, 4 \mathrm{CPA}$, and the nanohybrid, ZCPA.

The resulting material was then powdered and stored in a sample bottle for further use and characterisation.

Powder X-ray diffraction patterns were recorded at $2-60^{\circ}$ on a Shimadzu diffractometer XRD-6000 using $\mathrm{Cu} \mathrm{K} \mathrm{K}_{\alpha}$ radiation at $40 \mathrm{kV}$ and $30 \mathrm{~mA}$. FTIR spectra of the materials were recorded over the range $400-4000 \mathrm{~cm}^{-1}$ on a PerkinElmer 1752X spectrophotometer using the $\mathrm{KBr}$ disc method. A CHNS analyser, model CHNS-932 of LECO Instruments was used for CHNS analyses. Thermogravimetric and differential thermogravimetric analyses (TGA/DTG) were carried out using a Mettler Toledo instrument. Surface characterisation of the material was carried out using a nitrogen gas adsorption-desorption technique at $77 \mathrm{~K}$ using a Micromeritics ASAP 2000. The surface morphology of the samples was observed by a field emission scanning electron microscope (FESEM), using a JOEL JSM-6400. UVvis spectra were obtained using a Perkin Elmer UV-Visible Spectrophotometer, Lambda 35. Surface analysis of the nanohybrid in powder form was studied using an X-ray Photoelectron Spectrometer (XPS), Kratos Ultra. Samples were analysed at $1 \times 10^{-9}$ torr using monochromatic $\mathrm{AlK}_{\alpha}$ as the X-ray source and data were collected based on wide and narrow scans of the elements of interest.

\section{Results and Discussion}

3.1. Powder X-Ray Diffraction. The powder X-ray diffraction (PXRD) patterns of $\mathrm{ZnO}, 4 \mathrm{CPA}$, and the nanohybrids prepared using $0.05,0.10$, and $0.20 \mathrm{M} 4 \mathrm{CPA}$ are shown in Figure 1. The PXRD patterns of $\mathrm{ZnO}$ show that the sample was of a pure phase with good crystallinity as shown by the presence of typical $\mathrm{ZnO}$ peak patterns (Table 1).

The resulting materials obtained by direct reaction between $\mathrm{ZnO}$ and $4 \mathrm{CPA}(0.05-0.20 \mathrm{M})$ showed well-ordered 2D-layered nanohybrids, labelled as ZCPAs. The average basal spacing of 21.26 and $21.14 \AA$ was observed when 0.05 
TABLE 1: Carbon and hydrogen content, surface area and thermal property of ZnO, 4CPA, and ZCPA nanohybrid and the kinetic equations used for the fitting.

(a)

\begin{tabular}{|c|c|c|c|c|c|}
\hline \multirow{2}{*}{ Sample } & \multicolumn{2}{|c|}{ Mass (\%) } & \multirow{2}{*}{ Loading (\%) } & \multirow{2}{*}{ BET surface area $/ \mathrm{m}^{2} \mathrm{~g}^{-1}$} & \multirow{2}{*}{ BJH pore diameter $/ \AA$} \\
\hline & Carbon & Hydrogen & & & \\
\hline $4 \mathrm{CPA}$ & 51.2 & 4.089 & - & - & - \\
\hline $\mathrm{ZCPA}(\mathrm{ZnO})$ & 21.9 & 3.141 & 45.4 & $6.1(3.9)$ & $138(208)$ \\
\hline
\end{tabular}

(b) XPS analysis (value in Ev)

\begin{tabular}{|c|c|c|c|c|c|c|}
\hline & $\mathrm{C}_{1 \mathrm{~S}}$ & $\mathrm{O}_{1 \mathrm{~S}}$ & $\mathrm{Zn}_{\mathrm{p}_{3 / 2}}$ & $\mathrm{Zn}_{\mathrm{p}_{1 / 2}}$ & $\mathrm{Cl}_{\mathrm{p}_{3 / 2}}$ & $\mathrm{Cl}_{\mathrm{p}_{1 / 2}}$ \\
\hline \multirow{3}{*}{ ZCPA } & 284.5 & 531.3 & 1021.7 & 1044.8 & 200.2 & 201.8 \\
\hline & 286.0 & 533.1 & - & - & - & - \\
\hline & 288.4 & - & - & - & - & - \\
\hline
\end{tabular}

(c) Thermal property

\begin{tabular}{|c|c|c|c|c|c|c|c|c|}
\hline & $T_{\max } /{ }^{\circ} \mathrm{C}$ & $\Delta \mathrm{m} / \%$ & $T_{\max } /{ }^{\circ} \mathrm{C}$ & $\Delta \mathrm{m} / \%$ & $T_{\max } /{ }^{\circ} \mathrm{C}$ & $\Delta \mathrm{m} / \%$ & $T_{\max } /{ }^{\circ} \mathrm{C}$ & $\Delta \mathrm{m} / \%$ \\
\hline $4 \mathrm{CPA}$ & - & - & - & - & 243.5 & 97.5 & - & - \\
\hline $\mathrm{ZnO}$ & 100.6 & 0.9 & - & - & - & - & - & - \\
\hline ZCPA & 92.6 & 6.8 & 155.0 & 6.2 & 294.4 & 30.1 & 952.1 & 20.5 \\
\hline
\end{tabular}

(d) ${ }^{a}$ Kinetic equations

\begin{tabular}{lccr}
\hline Zeroth order & First order & Pseudo-second-order & Parabolic diffusion \\
\hline$x=k t+c$ & $-\log (1-x)=k t+c$ & $t / M_{i}=1 / k_{2} M_{f}^{2}+\left(1 / M_{f}\right) \cdot t$ & $M_{i} / M_{f}=k t^{0.5}+c$ \\
\hline
\end{tabular}

${ }^{\mathrm{a}} x$ is the percentage release of $4 \mathrm{CPA}$ at time, $t(\mathrm{~min})$, and $c$ is a constant. $k, M_{i}$, and $M_{f}$ are the rate constant, the initial, and final concentration of $4 \mathrm{CPA}$, respectively.

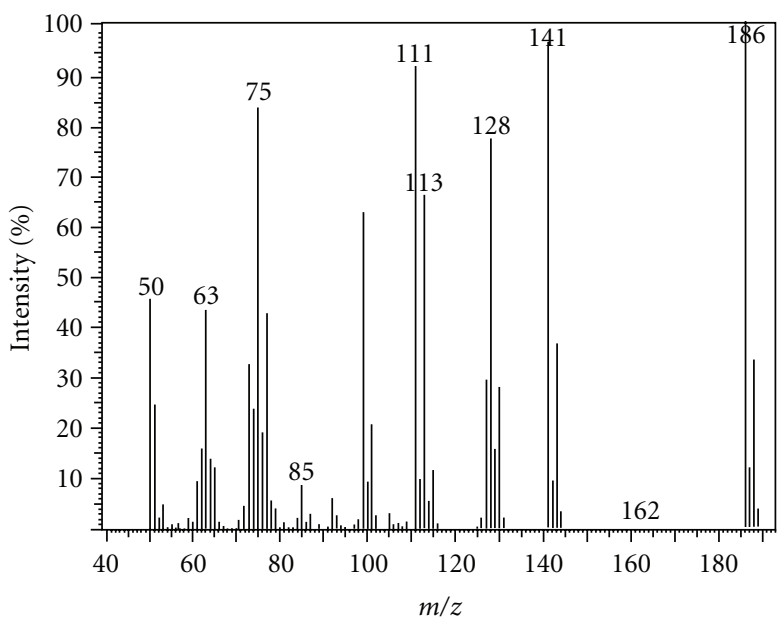

(a)

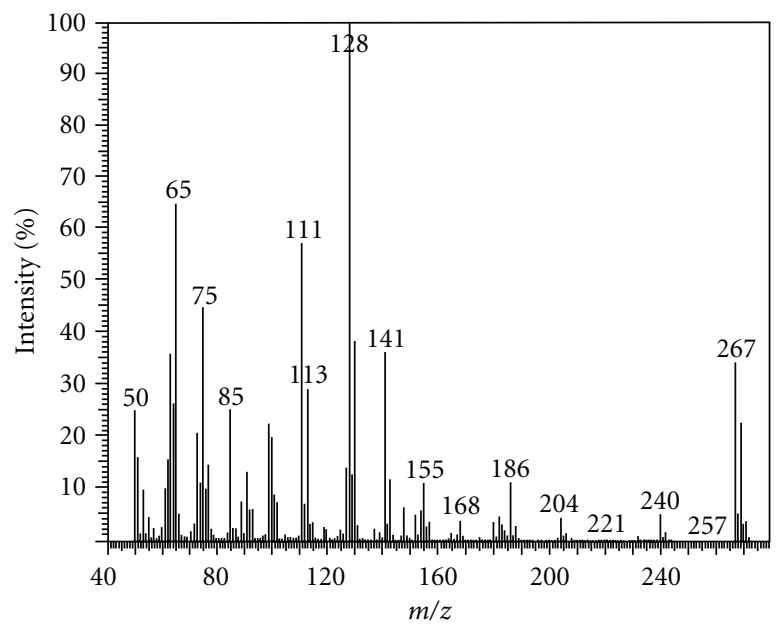

(b)

FIGURE 3: Direct injection mass spectra for 4-chlorophenoxyacetic acid, 4CPA (a), and its nanohybrid, ZCPA (b).

and $0.10 \mathrm{M} 4 \mathrm{CPA}$ was used, respectively, in the synthesis, compared to $19.03 \AA$ when $0.20 \mathrm{M} 4 \mathrm{CPA}$ was used (see Figure 1) with 4,3 , and 5 harmonics, respectively. This confirmed the formation of layered nanohybrids in which $\mathrm{ZnO}$ under an aqueous environment was transformed into a metal layered hydroxide, and at the same time, the intercalation of the 4CPA anion into the interlayer of the zinc-layered hydroxide took place.
It is believed that a "dissociation-deposition" mechanism governs the formation of the nanohybrid synthesised by a direct reaction between 4CPA and $\mathrm{ZnO}$ under an aqueous environment. $\mathrm{ZnO}$ was first hydrolysed followed by the formation of $\mathrm{Zn}(\mathrm{OH})_{2}$ on the surface of solid particles. The formation of $\mathrm{Zn}(\mathrm{OH})_{2}$ then subsequently formed thin layers on the oxide particle surfaces. The dissociation of $\mathrm{Zn}(\mathrm{OH})_{2}$ occurred at the solution-solid interface and formed $\mathrm{Zn}^{2+}$ 


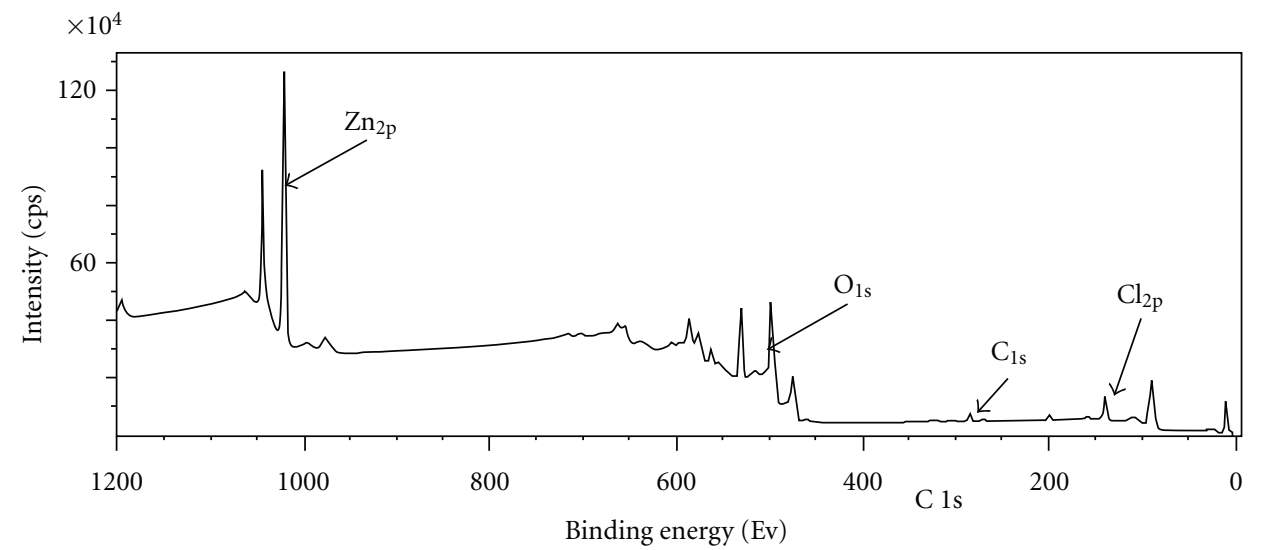

(a)

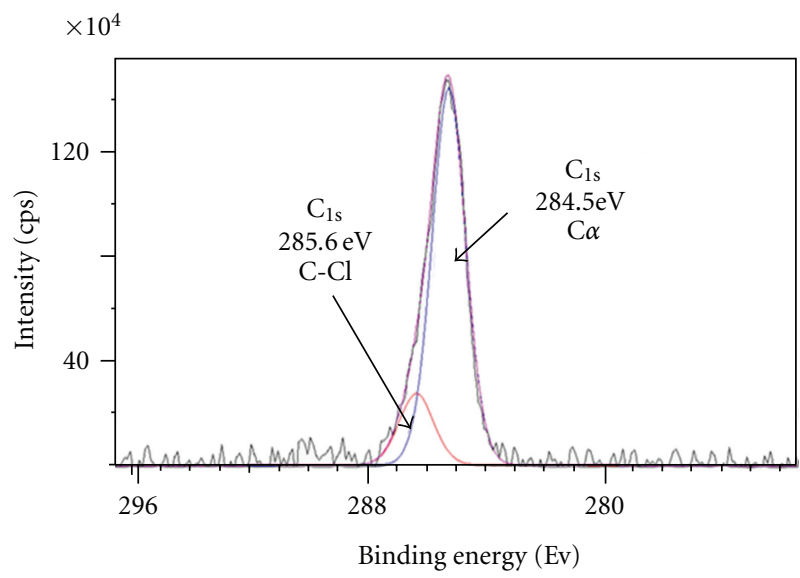

(b)

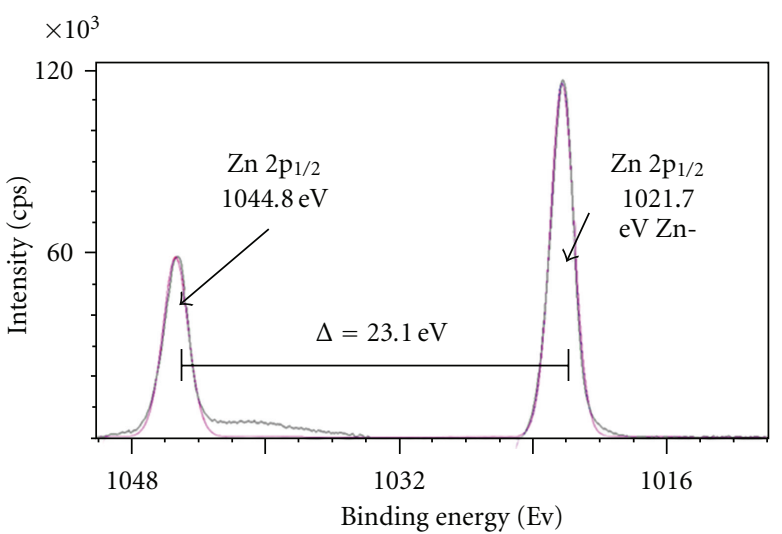

(d)

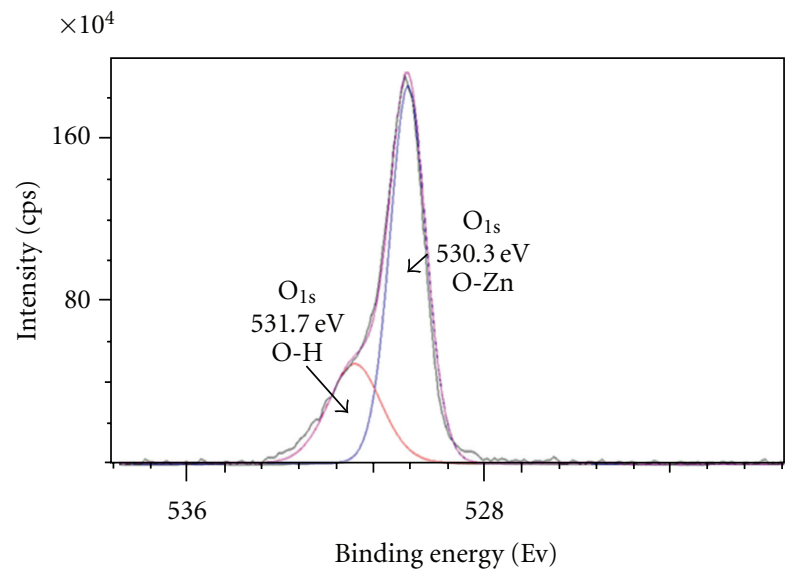

(c)

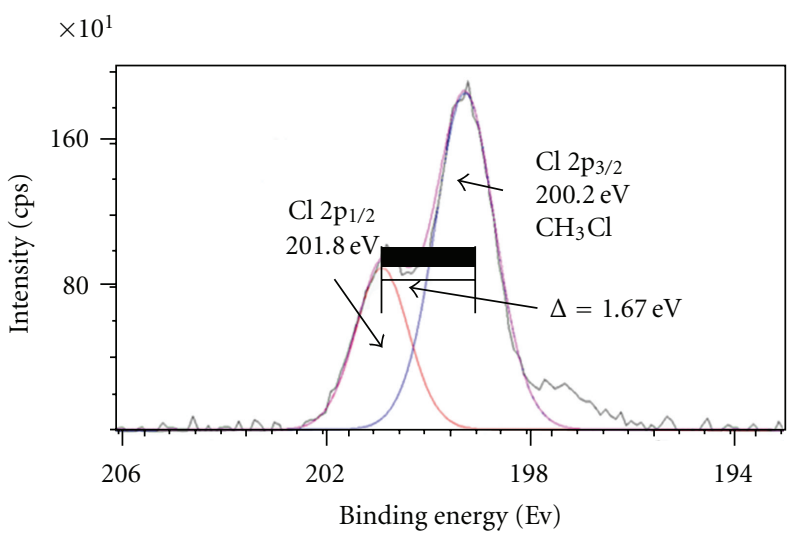

(e)

FIgURE 4: Wide (a) and narrow scan of XPS spectra of the nanohybrid, ZCPA for $\mathrm{C}_{1 \mathrm{~s}}$ (b), $\mathrm{O}_{1 \mathrm{~s}}(\mathrm{c}), \mathrm{Zn}_{2 \mathrm{p}},(\mathrm{d})$, and $\mathrm{Cl}_{2 \mathrm{p}}(\mathrm{e})$.

species. This species was then reacted with the hydroxyl group of $4 \mathrm{CPA}$ anions and water in solution, to generate the layered ZCPA nanohybrid. As a result, a nanolayered hybrid in which 4CPA was intercalated into the interlayer of zinclayered hydroxides was formed [20]. Also, shown in Figure 1, ZCPA nanohybrids synthesised using 0.10 and $0.20 \mathrm{M} 4 \mathrm{CPA}$ showed a relatively purer phase than the one synthesised at $0.05 \mathrm{M}$. The latter showed the presence of $\mathrm{ZnO}$, indicated by an incomplete reaction which resulted in the remaining $\mathrm{ZnO}$ phase. In contrast, no $\mathrm{ZnO}$ phase could be observed for the nanohybrids prepared at $0.10 \mathrm{M}$ and $0.20 \mathrm{M} 4 \mathrm{CPA}$, indicating that a complete reaction between the $4 \mathrm{CPA}$ anion and $\mathrm{ZnO}$ had taken place. As a result, the formation of phase pure zinc-layered hydroxide nanohybrid in which the 4CPA anion was completely intercalated into the inorganic interlayer host could be observed. The PXRD pattern of ZCPA synthesised at 0.20 M 4CPA showed a well-ordered nanolayered hybrid with up to five harmonics, from which the average basal spacing 


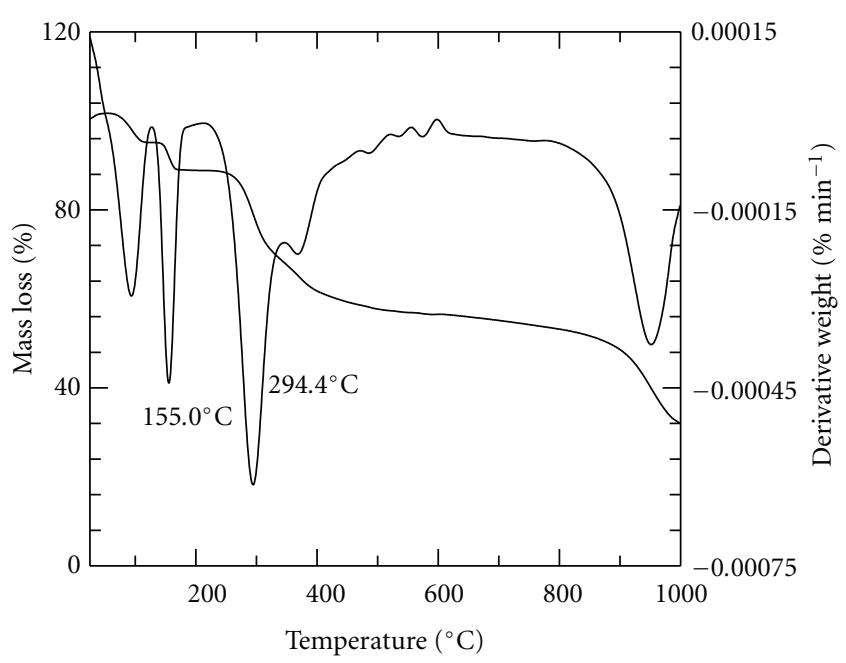

FIGURE 5: TGA/DTG thermogram of the ZCPA nanohybrid.

of $19.03 \AA$ of the material was deduced, showing a long-range order of the layer packing. The basal spacing was very similar to that of the 4CPA-Zn/Al-LDH nanohybrid, which is $20.1 \AA$ [21].

3.2. Fourier Transform Infrared. Figure 2 shows the FTIR spectra of $\mathrm{ZnO}, 4 \mathrm{CPA}$, and ZCPA. The FTIR spectrum of pure $\mathrm{ZnO}$ showed a band at $382 \mathrm{~cm}^{-1}$, which was due to zinc-oxygen sublattices [22]. For 4CPA, a broad absorption band at $3102 \mathrm{~cm}^{-1}$ was due to $\mathrm{O}-\mathrm{H}$ stretching vibration of the hydrogen-bonded and nonhydrogen-bonded hydroxyl groups from the hydroxide layers and interlayer water in 4CPA. The band at $2911 \mathrm{~cm}^{-1}$ was due to the presence of $\mathrm{C}-\mathrm{H}$ stretching vibrations of aromatic compounds. In addition, $\mathrm{H}-\mathrm{O}-\mathrm{H}$ bending vibration in 4CPA could be observed at $1873 \mathrm{~cm}^{-1}$ and a sharp, strong, and distinct band at $1705 \mathrm{~cm}^{-1}$ indicated the $\mathrm{C}=\mathrm{O}$ functional group. Both bands at $1487 \mathrm{~cm}^{-1}$ and $1426 \mathrm{~cm}^{-1}$ were attributed to the $\mathrm{C}=\mathrm{C}$ stretching vibration of the aromatic ring. The $\mathrm{C}-\mathrm{O}-\mathrm{C}$ stretching vibration was observed at $1230 \mathrm{~cm}^{-1}$ and a band at $703 \mathrm{~cm}^{-1}$ was due to the $\mathrm{C}-\mathrm{Cl}$ stretching vibration.

As shown in the figure, the nanohybrid ZCPA showed a broad absorption band at $3458 \mathrm{~cm}^{-1}$ which corresponded to the $\mathrm{O}-\mathrm{H}$ stretching vibration due to adsorbed and/or interlayer water. The band at $2970 \mathrm{~cm}^{-1}$ was due to the $\mathrm{C}-\mathrm{H}$ stretching vibration of the aromatic group while the $\mathrm{H}-\mathrm{O}-\mathrm{H}$ bending vibration for ZCPA was observed at $1888 \mathrm{~cm}^{-1}$. A band at $1547 \mathrm{~cm}^{-1}$ was due to the stretching vibration of aromatic compounds. Bands at $1487 \mathrm{~cm}^{-1}$ and $1409 \mathrm{~cm}^{-1}$ were attributed to the $\mathrm{C}=\mathrm{C}$ stretching vibration of the aromatic ring. Furthermore, the $\mathrm{C}-\mathrm{O}-\mathrm{C}$ stretching vibration was observed at $1220 \mathrm{~cm}^{-1}$ and a band at $713 \mathrm{~cm}^{-1}$ corresponded to the $\mathrm{C}-\mathrm{Cl}$ stretching band.

The FTIR spectrum of the ZCPA nanohybrid generally showed characteristic bands, indicating the contribution of 4CPA and $\mathrm{ZnO}$. These data demonstrate that the 4CPA anion had been intercalated into the interlayer of ZLH. However, some of the bands shown were slightly shifted in position, which indicated the existence of interactions between the
4CPA anionic guest and the ZLH host as a result of the formation of new bonds due to the intercalation process.

3.3. Organic Content, XPS, MS, and Thermal Studies. The organic loading of the ZCPA nanohybrid gave an indication of the degree of intercalation of $4 \mathrm{CPA}, \mathrm{C}_{8} \mathrm{H}_{6} \mathrm{ClO}_{3}$. If only adsorption of 4CPA occurred, then the XRD pattern of the resulting material should have been composed of the component phases separately, $\mathrm{ZnO}$ and 4CPA. The carbon and hydrogen contents of 4CPA and ZCPA nanohybrid obtained by CHNS analysis are shown in Table 1 . The results show that $4 \mathrm{CPA}$ contained $51.2 \%$ carbon compared to $21.9 \%$ for the nanohybrid, ZCPA. Therefore, the loading percentage of $4 \mathrm{CPA}$ in the nanohybrid of ZCPA was estimated to be $45.4 \%(\mathrm{w} / \mathrm{w})$. This result also confirmed the intercalation episode of the 4CPA anion into the inorganic interlayer of ZLH. Otherwise, adsorption of 4CPA occurred, resulting in the observation of the 4CPA phase in the resulting XRD patterns.

In order to confirm that the organic moiety that was actually intercalated into the ZLH interlamellae was 4CPA, the direct injection mass spectra (DIMS) were studied. The DIMS of 4CPA (Figure 3) showed major peaks at $\mathrm{m} / z$ values of $186,141,128,111,75,50$, and 28 and similar peaks could be also observed for the nanohybrid, ZCPA. The molecular ion at $m / z 186$ and 267 corresponded to the molecular formula of $4 \mathrm{CPA}\left(\mathrm{C}_{8} \mathrm{H}_{7} \mathrm{ClO}_{3}\right)$ and $\mathrm{C}_{8} \mathrm{H}_{6} \mathrm{ClO}_{3}-$ $\mathrm{ZnO}$, respectively. The latter particularly showed the formation of a bond between 4CPA and $\mathrm{Zn}-\mathrm{O}$ in the ZLH. Again, this demonstrated that the intercalation of $4 \mathrm{CPA}$ into ZLH had been successfully accomplished and confirmed the formation of the ZCPA nanohybrid in which the 4CPA organic moiety was bound with the inorganic ZLH cation, $\mathrm{Zn}$, in the interlamellae of ZLH.

XPS spectra of ZCPA nanohybrid are given in Figure 4 and the analysis is presented in Table 1. Generally, expected elements such as $\mathrm{C}, \mathrm{O}, \mathrm{Zn}$, and $\mathrm{Cl}$ were detected from a wide scan of the photoelectron peaks of the $\mathrm{C}_{1 \mathrm{~s}}, \mathrm{O}_{1 \mathrm{~s}}, \mathrm{Zn}_{2 \mathrm{p}}$, and $\mathrm{Cl}_{2 \mathrm{p}}$ spectra of the sample. The related binding energies were compared with references for their elemental chemical states [23]. Carbon $\left(\mathrm{C}_{1 \mathrm{~s}}\right)$ was observed mainly as a terminal hydrocarbon $\left(\mathrm{C}_{1 \mathrm{~s}}=284.5 \mathrm{eV}\right)$ and $\mathrm{C}-\mathrm{Cl}$ from 4CPA. Oxygen $\left(\mathrm{O}_{1 \mathrm{~s}}\right)$, observed at 530.3 and $531.7 \mathrm{eV}$ was due to $\mathrm{Zn}-\mathrm{O}$ and $-\mathrm{OH}$, respectively. There was only one chemical state of $\mathrm{Zn}\left(\mathrm{Zn}_{2 \mathrm{p} 3 / 2}\right)$ at $1021.7 \mathrm{eV}$ that could be observed in the XPS spectrum, which could be attributed to the $\mathrm{Zn}$ of $\mathrm{Zn}-$ $\mathrm{O}-\mathrm{H}$. Chlorine $\left(\mathrm{Cl}_{2 \mathrm{p} 3 / 2}\right)$ in the form of a single organochlorine was observed at a binding energy of $200.26 \mathrm{eV}$, which was expected from the 4CPA compound. In general, all the expected elements and their chemical states were in agreement with the assumption that organocompounds were bonded to $\mathrm{Zn}$. This shows that the organic moiety, 4CPA was directly bonded to $\mathrm{Zn}$, and that it was intercalated between ZLH interlayers in agreement with the DIMS study.

Thermogravimetric analysis of 4CPA showed a strong, intense, and sharp peak at a temperature maximum of $243.5^{\circ} \mathrm{C}$ with weight loss of $97.5 \%$ (Table 1 ). This corresponded to complete decomposition of the organic 


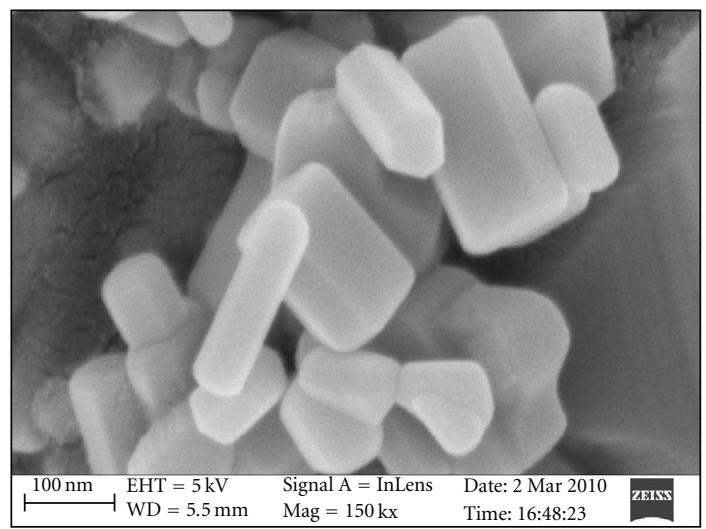

(a)

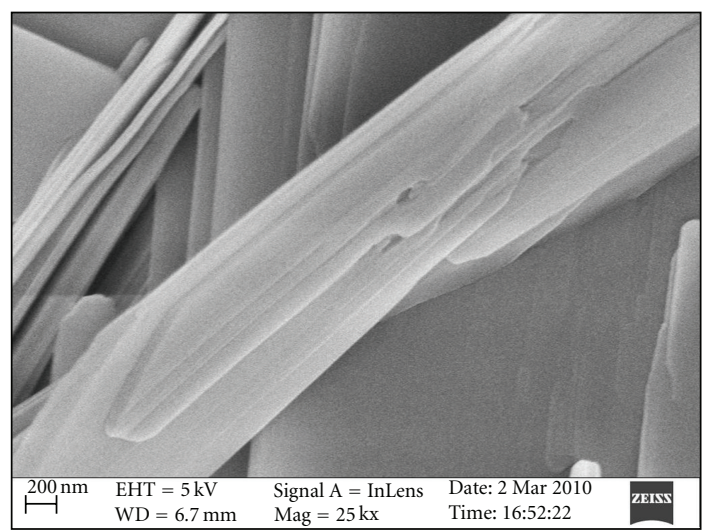

(b)

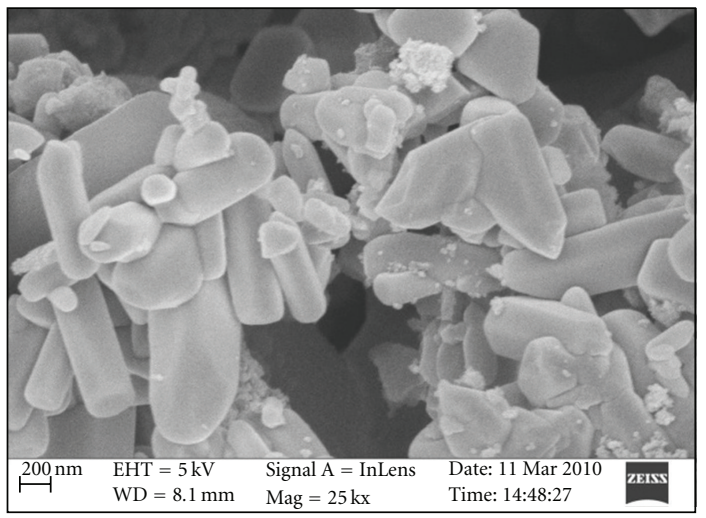

(c)

Figure 6: Field emission scanning electron micrographs of $\mathrm{ZnO}$ (a), the nanohybrid (b), and the nanohybrid heated at $500^{\circ} \mathrm{C}$ for $5 \mathrm{~h}(\mathrm{c})$.

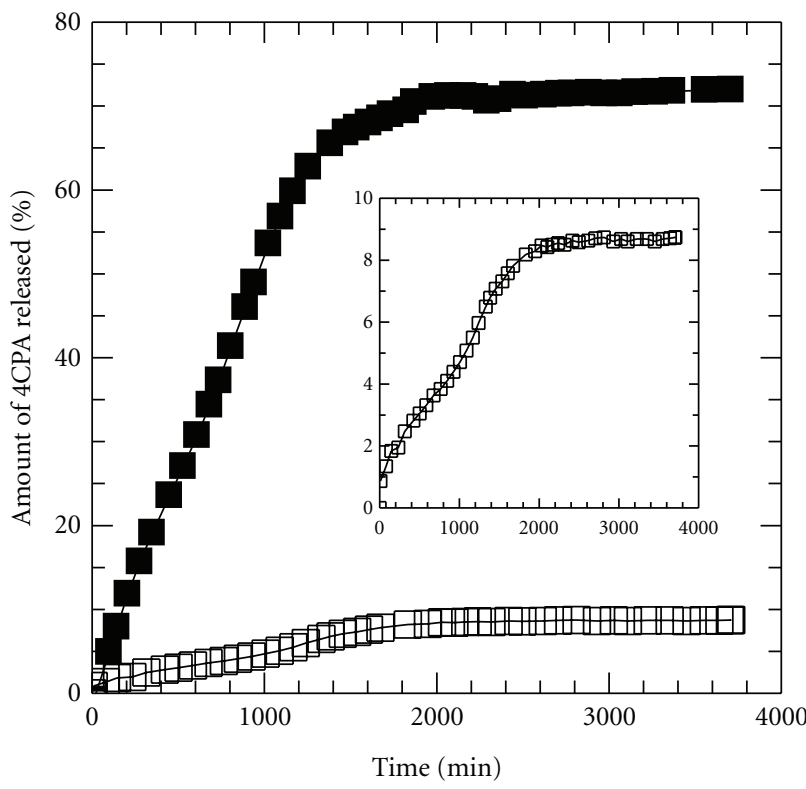

FIGURE 7: Release profiles of 4CPA from the interlamellae of the ZCPA nanohybrid into $\mathrm{Na}_{2} \mathrm{CO}_{3}$ aqueous solutions, $0.001 \mathrm{M}$ (opened symbol, also, shows in the inset with $y$-axis expanded) and $0.002 \mathrm{M}$ (closed symbol). compound, 4CPA. For ZCPA, there were four intense and sharp peaks that could be seen clearly. The first temperature maximum was at $92.6^{\circ} \mathrm{C}$ with a weight loss of $6.8 \%$. This was due to the removal of surface physisorbed water molecules. The weight loss of $6.2 \%$ at $155.0^{\circ} \mathrm{C}$ was attributed to the removal of interlayer anions and dehydroxylation of the hydroxyl layer. About $30.1 \%$ weight loss at $294.4^{\circ} \mathrm{C}$ was due to the decomposition of the intercalated organic moiety, the 4CPA anion, between the inorganic-ZLH layers (Figure 5).

The thermal study showed that 4CPA intercalated into the inorganic host, ZLH was thermally more stable than its counterpart in the nonintercalated form. TGA/DTG thermograms of $\mathrm{ZnO}$ showed that it was a very stable compound thermally with weight loss of $0.9 \%$ at $100.6^{\circ} \mathrm{C}$, attributed to surface-adsorbed water molecule from the atmosphere.

3.4. Surface Morphology and Surface Area. Field emission scanning electron microscope (FESEM) was used to study the surface morphology of the materials. The surface morphology of $\mathrm{ZnO}$ showed well-defined hexagonal and square-like structures with various shapes and sizes at the nanometre scale. This structure was transformed into a thin, sheet-like structure when the ZCPA nanohybrid was formed 

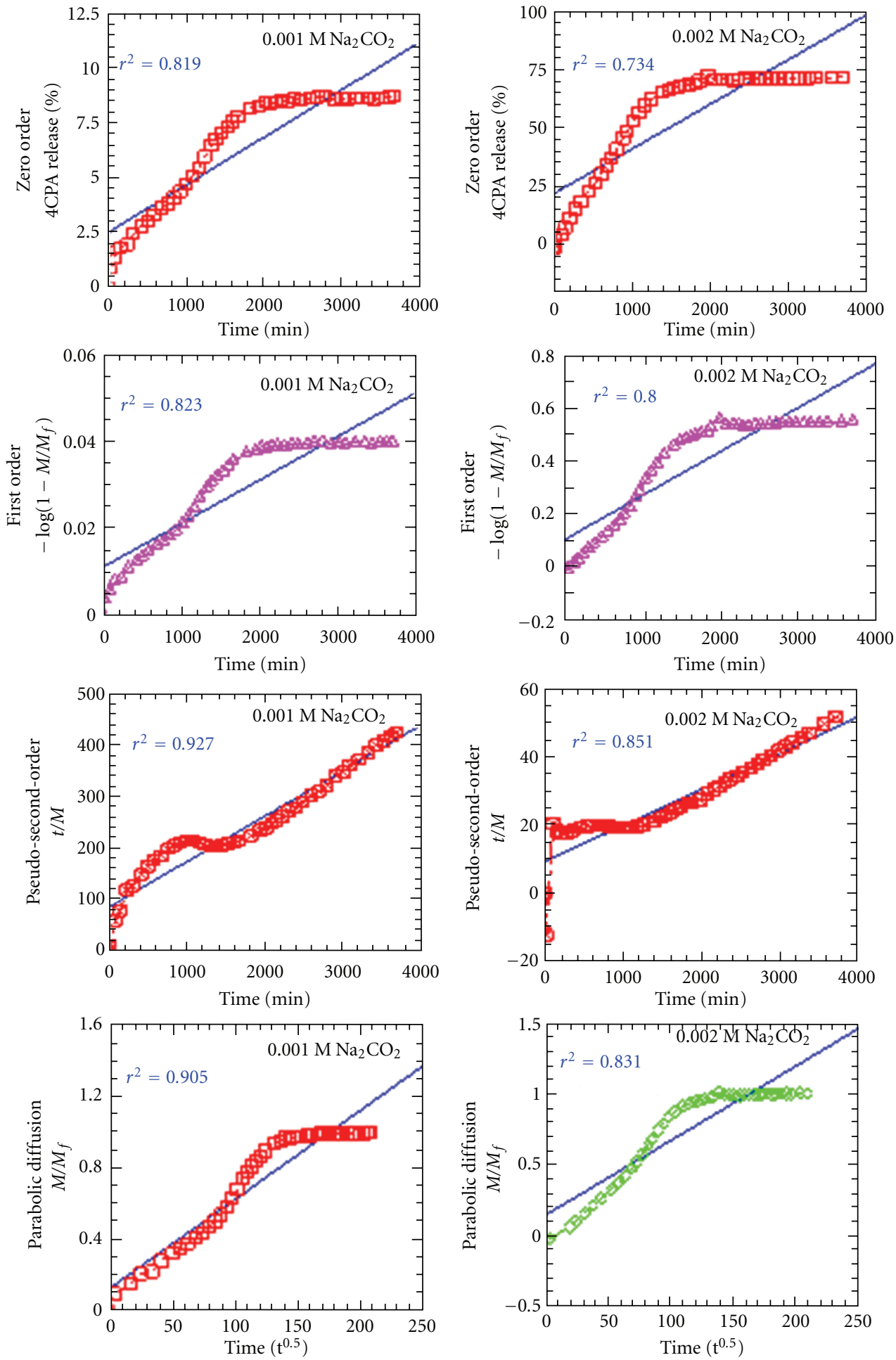

Figure 8: Fitting of the data of 4CPA released from the nanohybrid into $\mathrm{Na}_{2} \mathrm{CO}_{3}$ aqueous solutions to the zeroth-, first-, pseudo-secondorder, and parabolic diffusion using $0.001 \mathrm{M}$ and $0.002 \mathrm{M}$.

by a direct reaction of $\mathrm{ZnO}$ with $4 \mathrm{CPA}$ under an aqueous environment, as shown in Figure 6. This showed that the intercalation of 4CPA into the interlayer of zinc-layered hydroxide resulted in a change of the surface morphology from a well-defined fine hexagonal- and square-like structure to a thin, sheet-like structure with a thickness in the nanometre range. This is slightly different compared to the rosette-like structure that has been observed for the [4-(2,4dichlorophenoxybutyrate)-zinc-layered hydroxide] nanohybrid [23]. 
When the ZCPA nanohybrid was calcined at $500^{\circ} \mathrm{C}$ for $5 \mathrm{~h}$, the structure of thin, sheet-like nanostructures was transformed back to the original $\mathrm{ZnO}$ structure (Figure 6(c)) reverting back to the irregular hexagonal- and square-like structure. This indicated that the organic moiety, 4CPA, intercalated into the interlayer of inorganic ZLH and was completely decomposed by heating at $500^{\circ} \mathrm{C}$. At the same time, the $\mathrm{Zn}$ component was oxidised, resulting in the formation of $\mathrm{ZnO}$.

The BET surface area was measured for $\mathrm{ZnO}$ and ZCPA by the gas adsorption technique and the surface areas were determined to be 4 and $6 \mathrm{~m}^{2} / \mathrm{g}$, respectively, (Table 1 ). Relative to $\mathrm{ZnO}$, the intercalation resulted in an increase of the BET-specific surface area by about 50\%. This is in agreement with the formation of mesopores (Type IV isotherm) created by the formation of a layered ZCPA nanohybrid.

3.5. Controlled Release and Kinetics. Figure 7 shows the release profiles of $4 \mathrm{CPA}$ from the interlamellae of the ZCPA nanohybrid into 0.001 and $0.002 \mathrm{M} \mathrm{Na}_{2} \mathrm{CO}_{3}$ aqueous solutions. As shown in the figure, the accumulated $4 \mathrm{CPA}$ released into the aqueous solution increased with contact time when ZCPA was placed in the aqueous solutions. For the $0.002 \mathrm{M} \mathrm{Na}_{2} \mathrm{CO}_{3}$ solution, the release rate was found to be rapid for the first 1400 minutes, followed by a sustained release thereafter. Equilibrium was achieved at around 1685 minutes with $65 \%$ of the 4CPA released from the interlayer of ZCPA. On the other hand, for the $0.001 \mathrm{M} \mathrm{Na}_{2} \mathrm{CO}_{3}$ aqueous solution, the amount of 4CPA released was found to be about $12 \%$ with a rapid release rate for the first 1450 minutes, followed by a slow release thereafter. Equilibrium was achieved at 1720 minutes. This result indicates that the higher the concentration of aqueous solution used, the higher the percentage release of 4CPA from the interlamellae of ZCPA nanohybrid. This was due to the higher concentration of carbonate from the aqueous solution to be ion-exchanged with 4CPA from the interlamellae of ZCPA nanohybrid material.

The release kinetics of 4CPA from the interlamellae of ZLH were evaluated using various kinetics models, namely, zeroth-, first-, pseudo-second order, as well as parabolic diffusion equations (Table 1 ).

An attempt was made to fit the data for 4CPA release into these equations, and the obtained results are shown in Figure 8. Linear regression $\left(r^{2}\right)$ showed that a pseudosecond-order kinetic model fit better than the other models used in this work with an $r^{2}$ value of 0.927 and 0.851 for $0.001 \mathrm{M}$ and $0.002 \mathrm{M}$ sodium carbonate, respectively. This shows that the release of the organic moiety from the inorganic ZLH interlamellae involved the dissolution of the nanohybrid as well as ion exchange between the intercalated anions in the interlamellae host and the carbonate anions in the aqueous solution which was controlled by pseudosecond-order kinetics. These results are very similar to the results of a previous study [21].

\section{Conclusions}

An organic-inorganic nanohybrid of zinc-layered hydroxide4-chlorophenoxyacetate can be prepared using a simple direct reaction of the 4CPA anion with $\mathrm{ZnO}$ under an aqueous environment. The concentration of 4CPA was found to be a controlling factor in determining the formation of a pure phase, well-ordered nanolayered hybrid material. The nanohybrid showed a controlled release property, and the release was governed by pseudo-second-order kinetics. Therefore, such a material could be used as a controlled release formulation of herbicides.

\section{Acknowledgments}

Funding for this research was provided by the Ministry of Higher Education of Malaysia (MOHE) under the FRGS Grant no. 02-11-08-615FR. N. F. Nazarudin thanks Jabatan Perkhidmatan Awam Malaysia for the scholarship.

\section{References}

[1] F. Cavani, F. Trifirò, and A. Vaccari, "Hydrotalcite-type anionic clays: preparation, properties and applications," Catalysis Today, vol. 11, no. 2, pp. 173-301, 1991.

[2] G. G. C. Arizaga, K. G. Satyanarayana, and F. Wypych, "Layered hydroxide salts: synthesis, properties and potential applications," Solid State Ionics, vol. 178, no. 15-18, pp. 11431162, 2007.

[3] S. Hamada, S. Hibarino, K. Ikeue, and M. Machida, "Preparation of supported Pt-M catalysts $(\mathrm{M}=\mathrm{Mo}$ and $\mathrm{W})$ from anion-exchanged hydrotalcites and their catalytic activity for low temperature $\mathrm{NO}-\mathrm{H}_{2}-\mathrm{O}_{2}$ reaction," Applied Catalysis B, vol. 74, no. 3-4, pp. 197-202, 2007.

[4] C. S. Cordeiro, G. G. C. Arizaga, L. P. Ramos, and F. Wypych, "A new zinc hydroxide nitrate heterogeneous catalyst for the esterification of free fatty acids and the transesterification of vegetable oils," Catalysis Communications, vol. 9, no. 11-12, pp. 2140-2143, 2008.

[5] P. Nalawade, B. Aware, V. J. Kadam, and R. S. Hirlekar, "Layered double hydroxides: a review," Journal of Scientific and Industrial Research, vol. 68, no. 4, pp. 267-272, 2009.

[6] L. Poul, N. Jouini, and F. Fievet, "Layered hydroxide metal acetates (metal = zinc, cobalt, and nickel): elaboration via hydrolysis in polyol medium and comparative study," Chemistry of Materials, vol. 12, no. 10, pp. 3123-3132, 2000.

[7] M. J. Masarudin, K. Yusoff, R. A. Rahim, and M. Z. Hussein, "Successful transfer of plasmid DNA into in vitro cells transfected with an inorganic plasmid-Mg/Al-LDH nanobiocomposite material as a vector for gene expression," Nanotechnology, vol. 20, no. 4, Article ID 045602, 2009.

[8] V. Ambrogi, G. Fardella, G. Grandolini, and L. Perioli, "Intercalation compounds of hydrotalcite-like anionic clays with antiinflammatory agents-I. Intercalation and in vitro release of ibuprofen," International Journal of Pharmaceutics, vol. 220, no. 1-2, pp. 23-32, 2001.

[9] H. Zhang, K. Zou, S. Guo, and X. Duan, "Nanostructural drug-inorganic clay composites: structure, thermal property and in vitro release of captopril-intercalated $\mathrm{Mg}$-Al-layered double hydroxides," Journal of Solid State Chemistry, vol. 179, no. 6, pp. 1792-1801, 2006. 
[10] M. Z. B. Hussein, N. Hashim, A. H. Yahaya, and Z. Zainal, "Controlled release formulation of agrochemical pesticide based on 4-(2,4-dichlorophenoxy)butyrate nanohybrid," Journal of Nanoscience and Nanotechnology, vol. 9, no. 3, pp. 21402147, 2009.

[11] M. Z. Hussein, A. M. Jaafar, A. H. Yahaya, and Z. Zainal, "The effect of single, binary and ternary anions of chloride, carbonate and phosphate on the release of 2,4dichlorophenoxyacetate intercalated into the $\mathrm{Zn}$-Al-layered double hydroxide nanohybrid," Nanoscale Research Letters, vol. 4, no. 11, pp. 1351-1357, 2009.

[12] M. Z. Bin Hussein, Z. Zainal, A. H. Yahaya, and D. W. V. Foo, "Controlled release of a plant growth regulator, $\alpha$ naphthaleneacetate from the lamella of $\mathrm{Zn}$-Al-layered double hydroxide nanocomposite," Journal of Controlled Release, vol. 82, no. 2-3, pp. 417-427, 2002.

[13] M. Z. B. Hussein and C. W. Long, "Synthesis of organomineral nanohybrid material: indole-2-carboxylate in the lamella of Zn-Al-layered double hydroxide," Materials Chemistry and Physics, vol. 85, no. 2-3, pp. 427-431, 2004.

[14] M. Z. B. Hussein, S. H. Sarijo, A. H. Yahaya, and Z. Zainal, "Synthesis of 4-chlorophenoxyacetate-zinc-aluminium-layered double hydroxide nanocomposite: physico-chemical and controlled release properties," Journal of Nanoscience and Nanotechnology, vol. 7, no. 8, pp. 2852-2862, 2007.

[15] W. Stählin and H. R. Oswald, "The crystal structure of zinc hydroxide nitrate, $\mathrm{Zn}_{5}(\mathrm{OH})_{8}\left(\mathrm{NO}_{3}\right)_{2} \cdot 2 \mathrm{H}_{2} \mathrm{O}$," Acta Crystallographica, vol. 26, pp. 860-863, 1970.

[16] S. M. Lu and S. F. Lee, "Slow release of urea through latex film," Journal of Controlled Release, vol. 18, no. 2, pp. 171-180, 1992.

[17] M. A. Teixeira, W. J. Paterson, E. J. Dunn, Q. Li, B. K. Hunter, and M. F. A. Goosen, "Assessment of chitosan gels for the controlled release of agrochemicals," Industrial and Engineering Chemistry Research, vol. 29, no. 7, pp. 1205-1209, 1990.

[18] G. G. Allan, C. S. Chopra, A. N. Neogi, and R. M. Wilkins, "Design and synthesis of controlled release pesticide-polymer combinations," Nature, vol. 234, no. 5328, pp. 349-351, 1971.

[19] L. P. Cardoso, R. Celis, J. Cornejo, and J. B. Valim, "Layered double hydroxides as supports for the slow release of acid herbicides," Journal of Agricultural and Food Chemistry, vol. 54, no. 16, pp. 5968-5975, 2006.

[20] Z. Xingfu, H. Zhaolin, F. Yiqun, C. Su, D. Weiping, and X. Nanping, "Microspheric organization of multilayered $\mathrm{ZnO}$ nanosheets with hierarchically porous structures," Journal of Physical Chemistry C, vol. 112, no. 31, pp. 11722-11728, 2008.

[21] S. H. Sarijo, M. Z. Hussein, A. H. J. Yahaya, and Z. Zainal, "Effect of incoming and outgoing exchangeable anions on the release kinetics of phenoxyherbicides nanohybrids," Journal of Hazardous Materials, vol. 182, no. 1-3, pp. 563-569, 2010.

[22] R. Muñoz-Espí, A. Chandra, and G. Wegner, "Crystal perfection in zinc oxide with occluded carboxyl-functionalized latex particles," Crystal Growth and Design, vol. 7, no. 9, pp. 15841589, 2007.

[23] X-ray Photoelectron Spectroscopy (XPS) Database, 2010, http://srdata.nist.gov/xps/selEnergyType.aspx. 

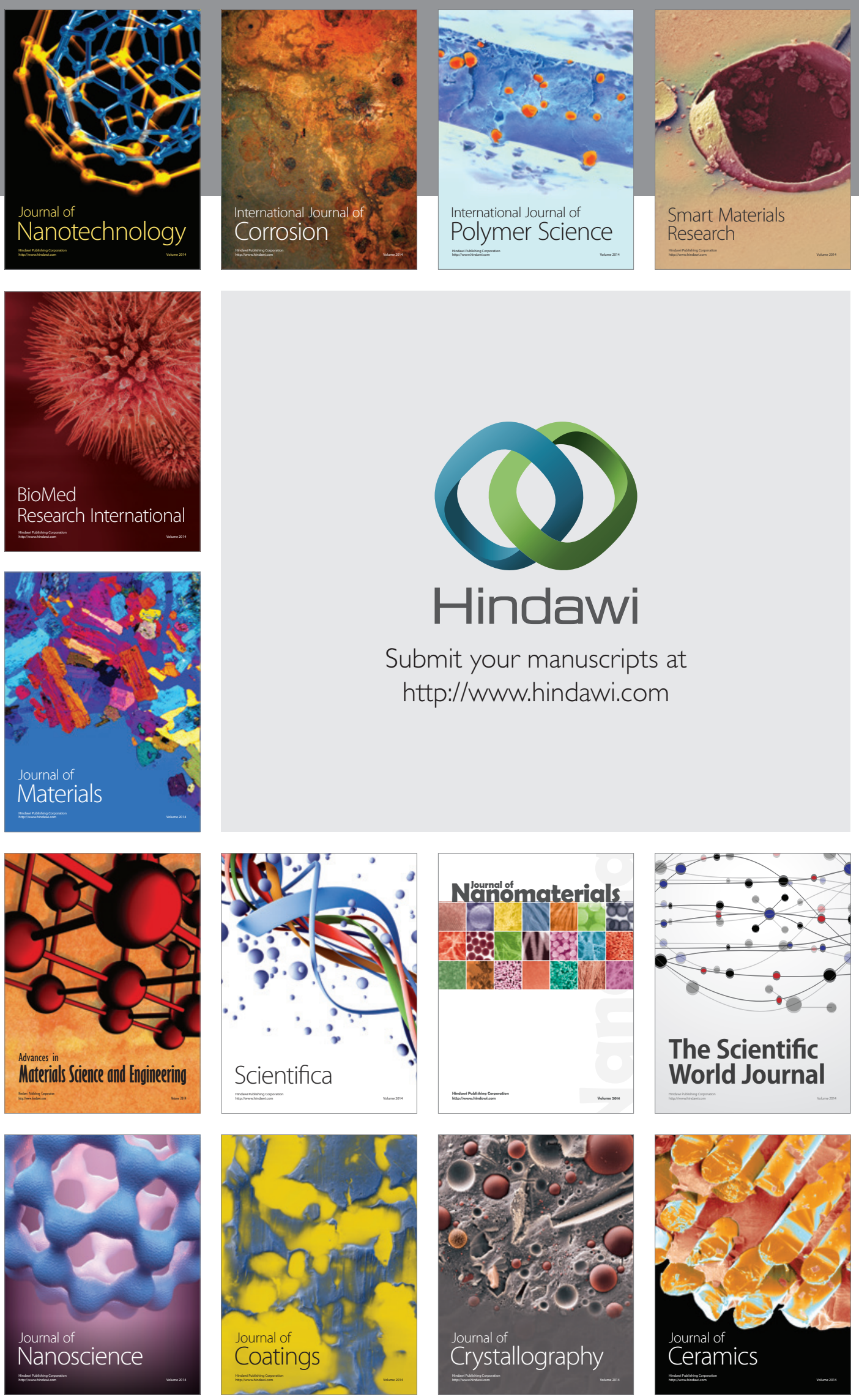

The Scientific World Journal

Submit your manuscripts at

http://www.hindawi.com

\section{World Journal}

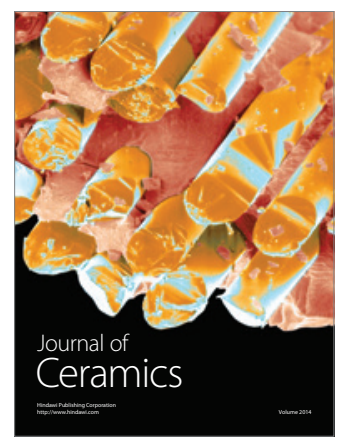

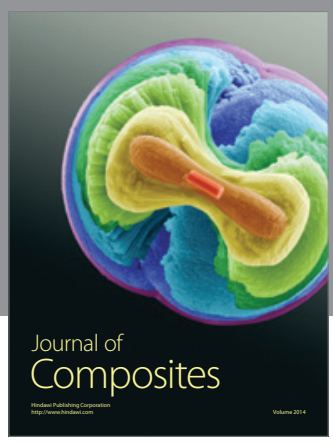
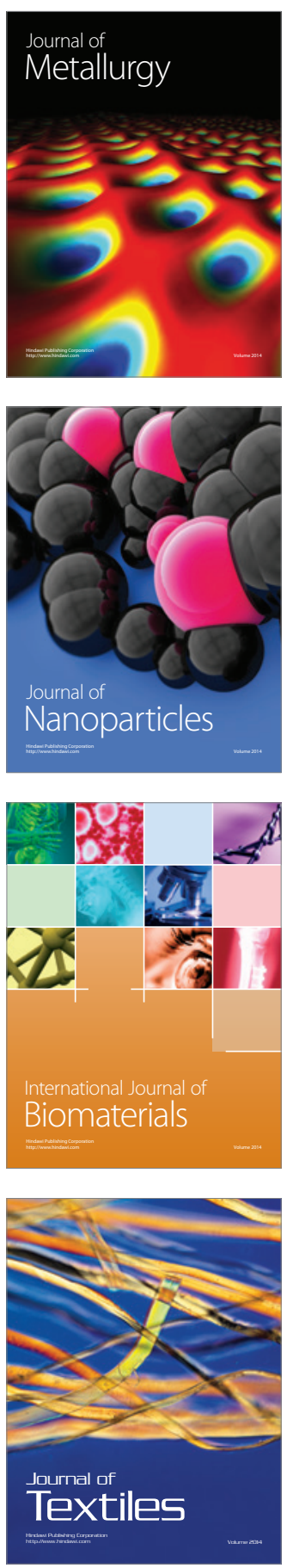